\title{
Evaluation of Antibiotics Ampicillin and Ciprofloxacin and Biosurfactant Rhamnolipid Effect on Hydrophobicity and Electron Donors and Recipients in Urinary and Fecal Escherichia Coli
}

\author{
Mahdi Khangholi, Shaghayegh Anvari, Ezzatollah Ghaemi, Ailar Jamalli* \\ Department of Microbiology, Faculty of Medicine, Golestan University of Medical Science, Gorgan, Iran \\ Email address: \\ Ailar_jamalli@goums.ac.ir (A. Jamalli) \\ ${ }^{*}$ Corresponding author \\ To cite this article: \\ Mahdi Khangholi, Shaghayegh Anvari, Ezzatollah Ghaemi, Ailar Jamalli. Evaluation of Antibiotics Ampicillin and Ciprofloxacin and \\ Biosurfactant Rhamnolipid Effect on Hydrophobicity and Electron Donors and Recipients in Urinary and Fecal Escherichia Coli. American \\ Journal of Life Sciences. Vol. 6, No. 3, 2018, pp. 39-46. doi: 10.11648/j.ajls.20180603.11
}

Received: July 27, 2018; Accepted: October 4, 2018; Published: November 6, 2018

\begin{abstract}
Adhesion is the first and most important stage in pathogenesis after bacteria enters to the body. Attachment of bacteria in medicine, industry, agriculture, waste decomposition, shipbuilding, etc. is important. Hydrophobicity and electron donor- electron acceptor characteristic are more important factors in bacterial adhesion. This study tries examining effect of biosurfactant rhamnolipid and two antibiotics ampicillin and ciprofloxacin on E. coli cell surface hydrophobicity and electron donor- electron acceptor characteristic by MATS method in terms of sample type and antibiotic resistance. Isolated bacteria from urine samples has a more antibiotic resistance to ampicillin. The results indicate that rhamnolipid makes increase in hydrophobicity and electron donor characteristic and in opposite ciprofloxacin makes increase electron acceptor and in opposite and decrease hydrophobicity. Also, hydrophobicity and electron donor- electron acceptor characteristic were different in sensitive and resistant to antibiotics strains. This study results showed since the hydrophobicity and electronic exchange are important factors involved in attachment of bacteria to inanimate surfaces and inner surfaces of the body, we can inhibit bacterial binding to it and help to reduce the incidence of antibiotic resistance by change these surfaces. The effect of antibiotics and rhamnolipid on some effective characteristic in adhesion cannot be ignored, despite the difference in their impact.
\end{abstract}

Keywords: Adhesion, Hydrophobicity, Electron Donor-electron Acceptor Characteristic

\section{Introduction}

Adhesion is the first and most important stage in pathogenesis after bacteria enters to the body [1]. An interaction between bacterial surface proteins and Target surface receptors which leads to the establishment of bacteria in the surface is called bacterial adhesion [2]. This process depends on Bacterial surface properties, surface characteristics and environmental conditions (such as the presence of serum and antibiotics and flow conditions) [3]. Also, attachment of bacteria to surface is the first stage in biofilm formation too $[4,5]$ whose least effect on health is causing to antibiotic resistance, impairments on drug absorption and change in the minimum inhibitory concentration of drug [6]. Attachment of bacteria to surfaces makes many problems in industry, medicine and nature so that it may even be the cause of human mortality [7]. It also may lead to increase the expression of genes responsible for coding bacterial virulence factors [2]. Some bacteria have secretary systems types 3, 4 and 6 that send effecter proteins into host cell by them that attachment is needed in this process too [8]. There are some effective factors in bacterial adhesion such as electrostatic and hydrophobic interactions and hydrogen bonds [9] and also the use of surface appendages such as flagella [10] and exopolysaccharides [4]. In general, bacterial adhesion includes primary and 
secondary phase [11]. In primary or initial phase, the physico-chemical interactions such as the Van der Waals and hydrophobic interactions happens between surface and the bacteria [11]. Other conditions like electron donors and recipients [12], surface charge, and perhaps chemotaxis help this process [11]. The initial phase makes the adhesion possible and arrivals in secondary phase [11]. At this stage, the connection is reversible [1]. In the second phase there are molecular and cellular interactions that make strengthen connections through optional bridging between bacterial surface polymeric structures (such as pili, capsule and $\mathrm{S}$ layer) and target surface [11] Ultimately they lead to irreversible adhesion [1]. This two-step and different mechanism of adhesion can be a target for vaccine production [2]. One of the main factors affecting the adhesion is hydrophobicity which is so important in adhesion of bacteria and eukaryotes to surfaces [13]. In general, bacteria with hydrophobic surface properties prefer hydrophobic surface and bacteria with hydrophilic surface properties prefer hydrophilic surface for adhesion [11]. surface charge is another bacterial effective surface characteristic in adhesion [14] that is affected by environmental conditions such as $\mathrm{PH}$, medium and ionic strength [1]. Bacteria earns surface charge through the ionization of acid and base groups of bacterial cell wall [1]. Surface charge is also important in antibiotic-resistant so that protects bacteria with negative surface charge from cationic antibiotics by limiting their secretion [15]. The last proven theory about the physical adhesion is Electron donor-electron acceptor approach that according to which dipole intermolecular forces are less effective than acid( electron acceptor)- base( electron donor) and hydrogen bonding [11]. Strong influence of electron exchange in bacterial adhesion has been proved so that the energy from the electron exchange is two folds stronger than the Van der Waals forces [12].

E. coli is a member of Enterobacteriaceae family that is anaerobic gram-negative bacteria [3] and can cause three types of disease overall: UTI, systemic diseases and diarrheal / enteric diseases [16]. Strains that cause intestinal infections are a global outbreak and are able to cause infection in all age groups, so that only the type of enterotoxigenic is responsible for more than 650 million cases annually [3]. One of important bacteria that cause Extra-intestinal infections is uropathogenic Escherichia coli that is agent of $70 \%$ to $90 \%$ of urinary tract infections and 50\% of catheter-related UTI [17]. After decades of using antibiotics in bacterial treatment, today we are faced to new worrying challenge named antibiotic resistance that limits the use of antibiotics [18]. Also, the vaccine can not be used for many bacteria [18] that notes necessity of effort to find modern methods of prevention and treatment [18]. In recent years, many attempts have been performed to change bacterial and target surface properties (Anti adhesion therapy) in order to prevent infections based on inhibiting the adhesion. For this purpose, it is necessary to know the surface properties of bacteria [8]. One of the compounds which is used in this context is rhamnolipid biosurfactant whose effect on surface properties of bacteria has been proven $[19,20]$ also there are studies indicating that some antibiotics affect the bacterial surface properties $[8,21]$. Therefore, in this study two antibiotics, ampicillin and ciprofloxacin were selected -which there have been many reports of their resistance and sensitivity in Iran respectively- to evaluate the effects of antibiotic-resistant on the bacterial surface properties $[22,23]$.

\section{Material and Methods}

\subsection{Bacterial Isolates}

Twenty strains isolated from urinary samples of patients with urinary disorders and twenty strains isolated from stool samples of patients with gastrointestinal disorders admitted to hospitals Sayyad Shirazi, Taleghani and 5 Azar in Gorgan city were selected.

\subsection{Growth Conditions}

All strains were cultured in the EMB medium in $37^{\circ} \mathrm{C}$ for 24 hours. 18 to 20 hour cultures in TSB were required for MATH test. Cultures in Mueller Hinton Agar were used for assaying antibiogram. Also, strains were cultured in Mueller Hinton Broth for MIC determination.

\subsection{MIC Determination}

After performing Antibiogram by disk diffusion method, susceptible strains to ampicillin and ciprofloxacin were selected for Macrodilution MIC [24]. For this purpose, 13 sterile tubes were selected and $1 \mathrm{ml}$ of Mueller Hinton Broth was poured in each one. Then $1 \mathrm{ml}$ of medium containing the desired concentration of antibiotics (according to CLSI) was added to the first tube and then serial dilution was performed. $1 \mathrm{ml}$ of bacterial suspension at a concentration of $1.5 * 10^{5}$ was added to all tubes and they all were autoclaved. Tubes Number 11 and 12 and 13 were positive control( containing bacterial growth medium), control medium( containing $2 \mathrm{~mL}$ medium) and negative control( containing medium and antibiotics) respectively [25].

\subsection{Bacterial Treatment}

For rhamnolipid it was provided bacterial suspension with a $1 \mathrm{~g} /$ lit rhamnolipid concentration [26]. Then they were placed in a shaking incubator for 3 hours and then separated by centrifuge and bacteria were washed three times with sterile saline and finally were ready for MATH test. For bacterial treatment by antibiotics, 0.5 fold of MIC concentration was used [24].

\subsection{MATS}

First an 18 to 20-hour culture of the bacteria in the TSB culture medium was prepared. Then centrifuge was performed at $3000 \mathrm{rpm}$ for 15 minutes to separate the bacteria. To eliminate the effect of the medium, the bacteria were washed twice by sterile saline. A Suspension with the 
concentration of $1.5 * 10^{8}$ of bacteria was prepared and 2.4 $\mathrm{ml}$ from it was added to $0.4 \mathrm{ml}$ of hydrocarbon solvents including chloroform (acidic solvent and electron recipient), ethyl acetate (alkaline solvent and an electron donor), hexadecane (nonpolar and hydrophobic solvent) and decane (nonpolar and hydrophobic solvent). Tubes were left at room temperature for 15 minutes after a 90 second vortex. Then absorbance was read in a wavelength of $600 \mathrm{~nm}$ and the tendency (of adhesion) to each of the solvents was calculated by the following formula [27]:

$\%$ adhesion: $1-\left(\mathrm{A}_{1} / \mathrm{A}_{0}\right) * 100$

$\mathrm{A}_{0}$ : Absorbance before adding solvents

$\mathrm{A}_{1}$ : Absorbance after adding solvents

\subsection{Statistical Analysis}

Student's t-test was used to compare means of experiments, and $\mathrm{P}<0.05$ was considered statistically significant.

\section{Results}

\subsection{Antibiotic Resistant}

First, samples were examined in terms of sensitivity and resistance to ampicillin and ciprofloxacin by disk diffusion method after isolation of bacteria from clinical samples( There are some reports that they show high sensitivity and high resistance to these antibiotics respectively), according to which 18 and 7 urine samples were resistant to ampicillin and ciprofloxacin by respect( From a total of 20 urine samples); also 13 and 7 stool samples were resistant to ampicillin and ciprofloxacin by respect(From a total of 20 stool samples) ( table 1). Then MIC macrodilution method was performed for sensitive sample to these antibiotics and generally was obtained three concentrations (table 2).

Table 1. Sensitivity and resistance to ampicillin and ciprofloxacin in strains isolated from urinary and fecal samples. Number (percent).

\begin{tabular}{|c|c|c|c|c|c|c|c|c|}
\hline & Stool samples & & & & Urine samples & & & \\
\hline Antibiotic & Ciprofloxacin & & Ampicillin & & Ciprofloxacin & & Ampicillin & \\
\hline $\mathbf{S} / \mathbf{R}$ & Resistant & Sensitive & Resistant & Sensitive & Resistant & Sensitive & Resistant & Sensitive \\
\hline Number(Percent) & $7(35)$ & $13(65)$ & $13(65)$ & $7(35)$ & $7(35)$ & $13(65)$ & $18(90)$ & $2(10)$ \\
\hline
\end{tabular}

Table 2. Obtained concentrations from MIC of sensitive to ampicillin and ciprofloxacin strains.

\begin{tabular}{llll}
\hline & Stool samples & & Urine samples \\
\hline Antibiotic & Ciprofloxacin & Ampicillin & Ciprofloxacin \\
\hline $\mathrm{MIC}_{\mathrm{s}}$ & $0.5 \mu \mathrm{g} / \mathrm{ml}, 0.125 \mu \mathrm{g} / \mathrm{ml}, 0.0625 \mu \mathrm{g} / \mathrm{ml}, 0.0312 \mu \mathrm{g} / \mathrm{ml}$ & $8 \mu \mathrm{g} / \mathrm{ml}, 4 \mu \mathrm{g} / \mathrm{ml}, 2 \mu \mathrm{g} / \mathrm{ml}$ & $0.25 \mu \mathrm{g} / \mathrm{ml}, 0.125 \mu \mathrm{g} / \mathrm{ml}, 0.0625 \mu \mathrm{g} / \mathrm{ml} \quad 2 \mu \mathrm{g} / \mathrm{ml}$ \\
\hline
\end{tabular}

\subsection{MATS}

MATS (Microbial adhesion to solvents) test was performed in the next step. This test is based on the affinity to four hydrocarbon solvent, with specific physicochemical properties for each one. These solvents include: chloroform, ethyl acetate, hexadecane and decane that determine hydrophobicity and electron donor- acceptor characteristic based on hydrophobic surfaces tendency to hydrophobic surfaces and hydrophilic surfaces tendency to hydrophilic surfaces and also electron donor surfaces tendency to electron acceptor surfaces and vice versa. Based on it, $60 \%$ of urinary strains and $90 \%$ of fecal strains had hydrophobic properties (with high affinity to hexadecane and decane). Also, $75 \%$ of urinary strains and $85 \%$ of fecal strains have electron donor properties (with high affinity to chloroform). In general, fecal strains had significantly higher hydrophobicity than urinary samples and electron donor characteristic in fecal strains was more than urinary strains (Figure 1).

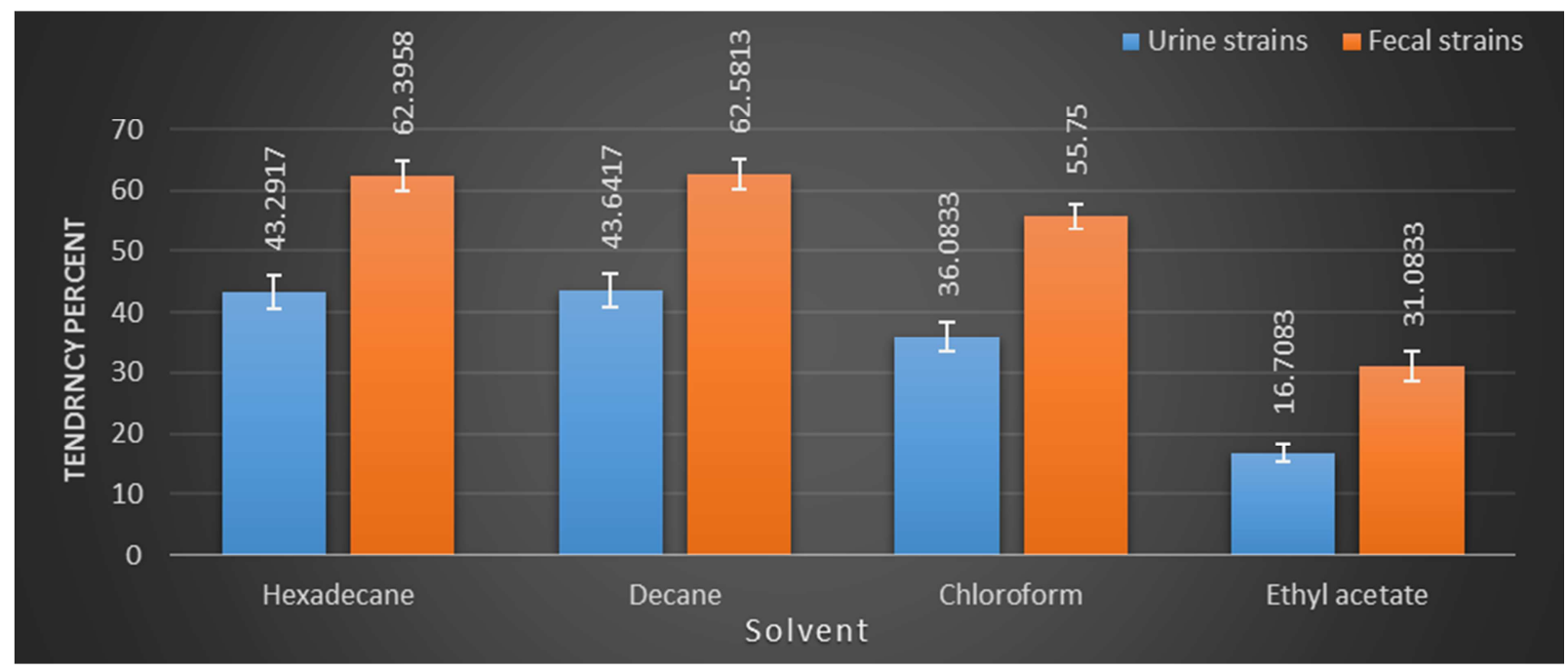

Figure 1. Comparison of hydrophobicity and electron donors and acceptor characteristic in strains isolated from urinary and fecal samples. 


\subsection{Urinary Strains Treatment with Rhamnolipid, Ampicillin and Ciprofloxacin}

The bacteria were treated for 3 hours in order to investigate bacteria surface properties that exposed to antibiotics and rhamnolipid. After urinary strains treatment with rhamnolipid, hydrophobicity and electron donor characteristic increased and electron acceptor characteristic decreased that was statistically significant $(\mathrm{P}$ value $<0.05)$. Urinary strains that were treated with ampicillin had a significant reduction in hydrophobicity but no effect of ampicillin was observed on electron donors-acceptor (Figure 2). After treatment of bacteria isolated from urine samples with ciprofloxacin, it was observed that concentrations $0.0625 \mu \mathrm{g} / \mathrm{ml}$ and $0.125 \mu \mathrm{g} / \mathrm{ml}$ decreased hydrophobicity and increase electron acceptor characteristic significantly, but there was no effect on the hydrophobicity by $0.0312 \mu \mathrm{g} / \mathrm{ml}$ and caused only a slight increase in electron acceptor characteristic (Figure 3).

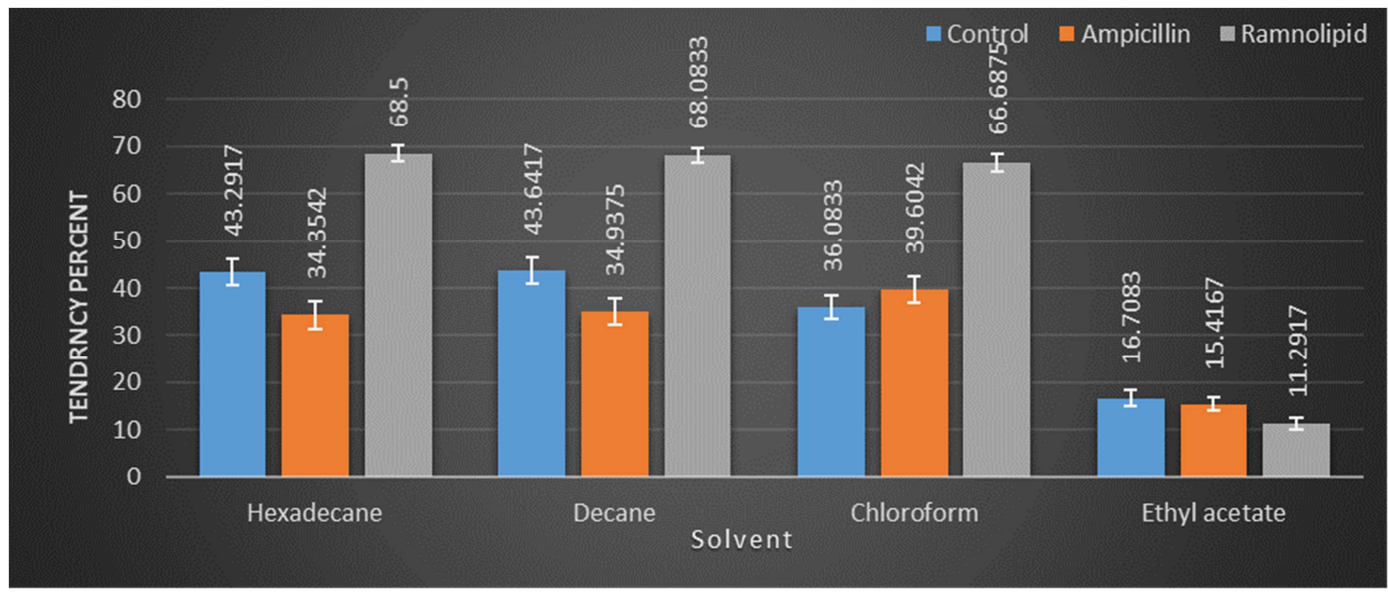

Figure 2. Effect of ampicillin and biosurfactant rhamnolipid on the urinary strains hydrophobicity and electron donors and acceptor characteristic.

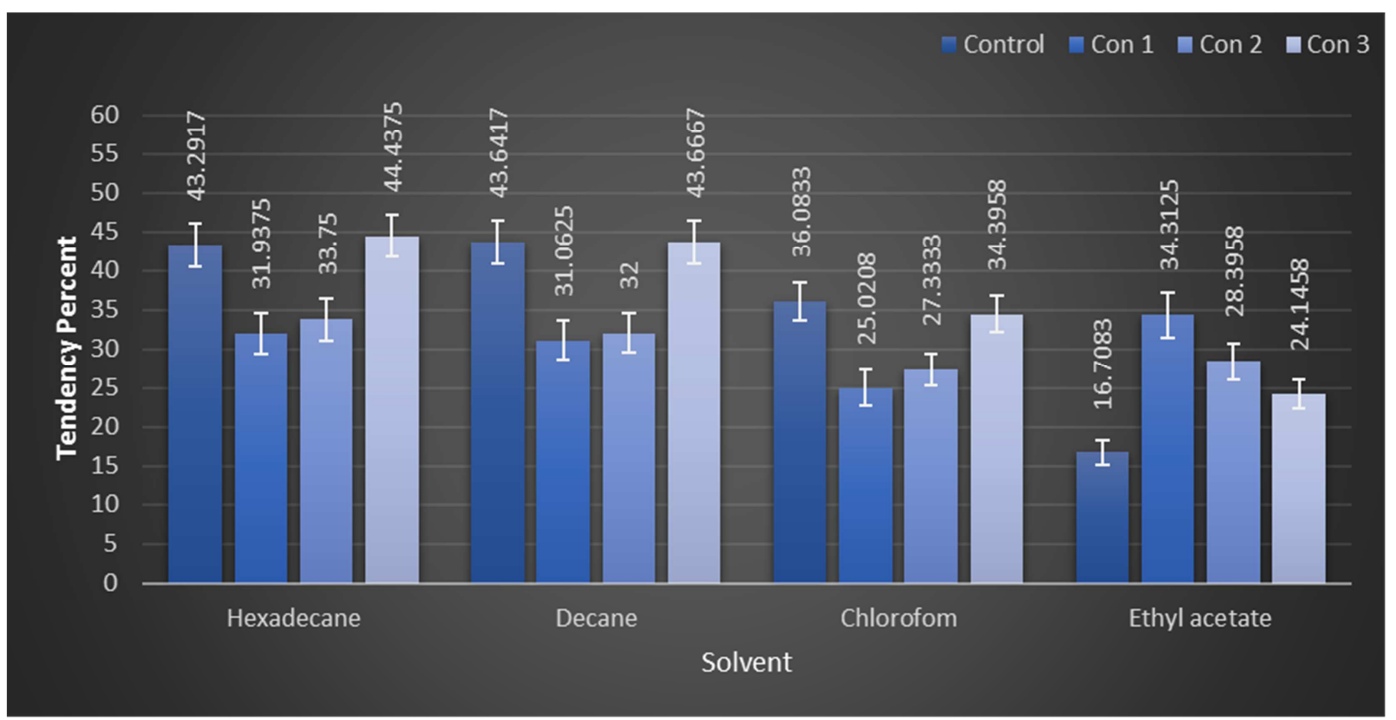

Figure 3. Hydrophobicity and electron donors and acceptor characteristic of urinary strains in different concentrations of ciprofloxacin (Con $1=$ concentration $0.125 \mu \mathrm{g} / \mathrm{ml}$, Con $2=$ concentration $0.0625 \mu \mathrm{g} / \mathrm{ml}$, Con $3=$ concentration $0.0312 \mu \mathrm{g} / \mathrm{ml}$ ).

\subsection{Fecal Strains Treatment with Rhamnolipid, Ampicillin and Ciprofloxacin}

Rhamnolipid increased hydrophobicity and electron donor characteristic and decreased electron acceptor characteristic in fecal samples (Figure 4). Three concentrations of ampicillin were used for fecal samples including: $1 \mu \mathrm{g} / \mathrm{ml}, 2$ $\mu \mathrm{g} / \mathrm{ml}$ and $4 \mu \mathrm{g} / \mathrm{ml}$. Concentrations $2 \mu \mathrm{g} / \mathrm{ml}$ and $4 \mu \mathrm{g} / \mathrm{ml}$ reduced hydrophobicity and increased electron acceptor characteristic but there was no obvious effect on the electron donor characteristic. Concentration $1 \mu \mathrm{g} / \mathrm{ml}$ reduced hydrophobicity and there was no effect on electron donoracceptor characteristic (Figure 5). Different concentrations of ciprofloxacin reduced hydrophobicity and electron donor characteristic and increased electron acceptor characteristic (Figure 6) while increased hydrophobicity and electron donor characteristic and reduced electron acceptor characteristic. 


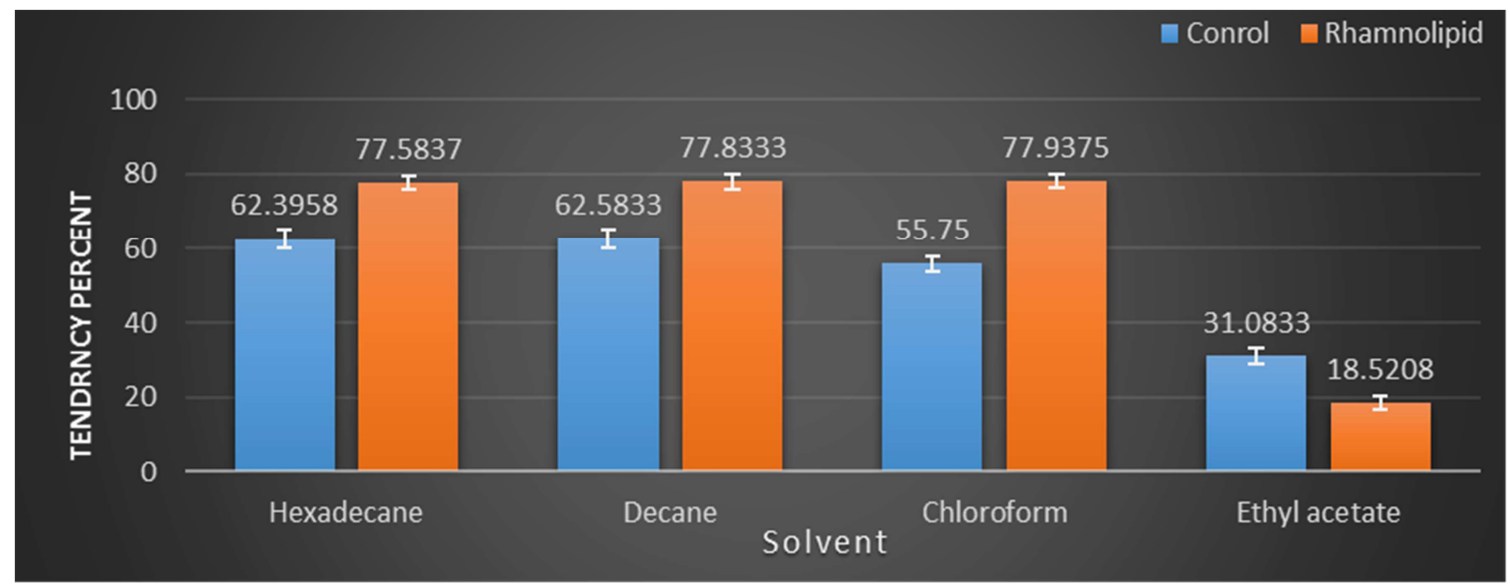

Figure 4. Hydrophobicity and electron donors and acceptor characteristic of fecal strains in the presence rhamnoliopd.

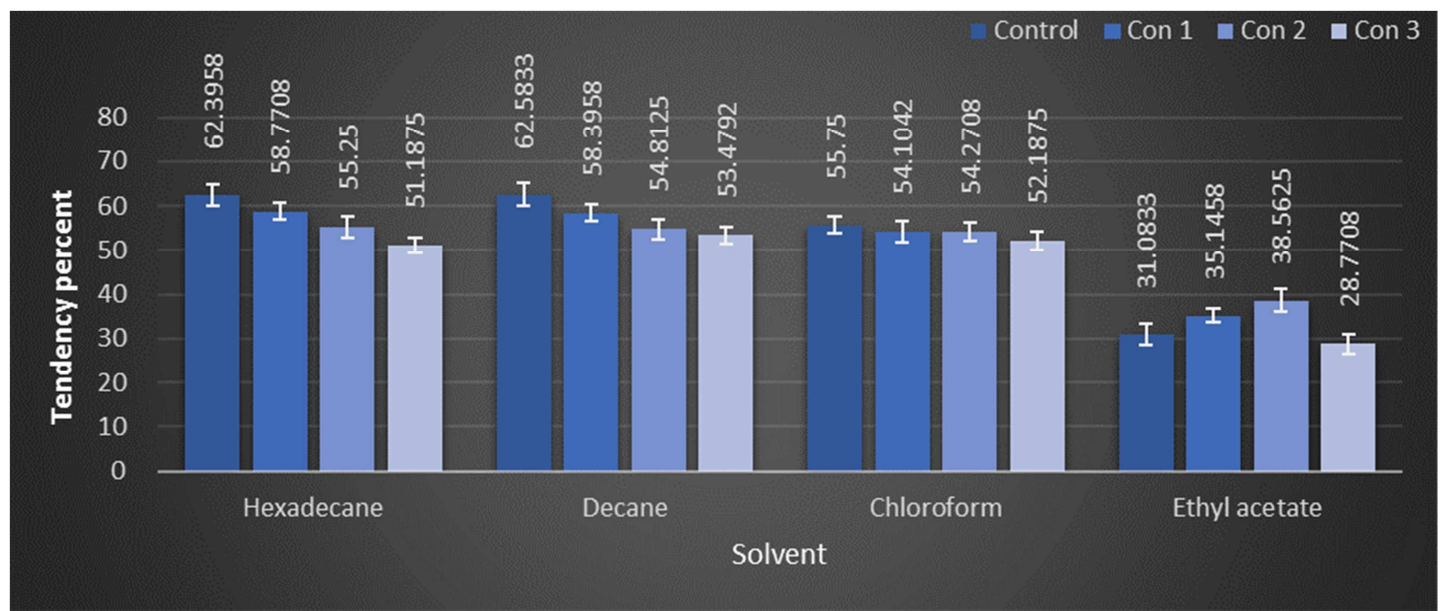

Figure 5. Hydrophobicity and electron donors and acceptor characteristic of fecal strains in the presence of various concentrations of ampicillin (Con $1=$ concentration $4 \mu \mathrm{g} / \mathrm{ml}$, Con $2=$ concentration $2 \mu \mathrm{g} / \mathrm{ml}$, Con $3=1$ concentration $\mu \mathrm{g} / \mathrm{ml})$.

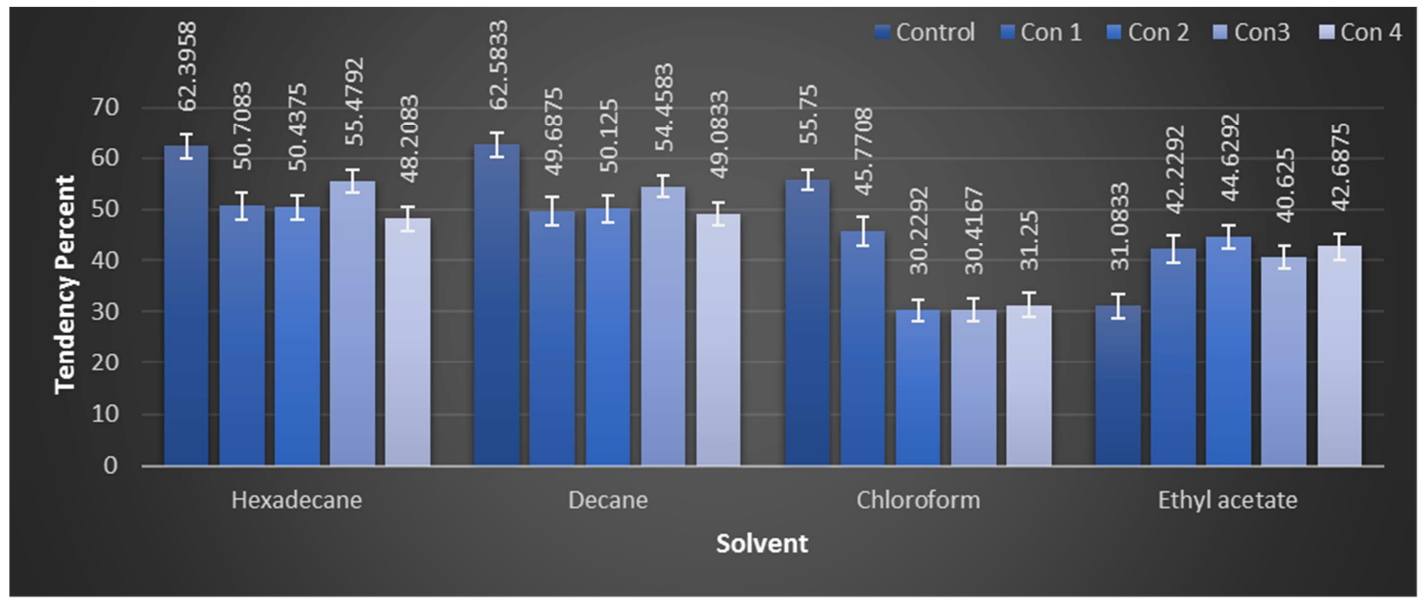

Figure 6. Hydrophobicity and electron donors and acceptor characteristic of fecal strains in the presence of various concentrations of ciprofloxacin (Con $1=$ concentration $0.25 \mu \mathrm{g} / \mathrm{ml}$, Con $2=$ concentration $0.0625 \mu \mathrm{g} / \mathrm{ml}$, Con $3=$ concentration $0.0312 \mu \mathrm{g} / \mathrm{ml}$, Con $4=$ concentration $0.0156 \mu \mathrm{g} / \mathrm{ml}$ ).

\subsection{Comparison of Surface Characteristics of Sensitive and Resistant Strains to Ampicillin}

E1. Urinary strains: In the following, hydrophobicity and electron donor- acceptor characteristic of sensitive and resistant urinary strains to ampicillin in the presence of ampicillin were compared which the results indicated that resistant strains had higher hydrophobicity and lower electron donor characteristic than sensitive strains.

E2. Fecal strains: Also, hydrophobicity and electron donor- acceptor characteristic of sensitive and resistant fecal strain to ampicillin in the presence of three concentrations of ampicillin (MIC50 concentration obtained from susceptible 
strains) were compared that results showed that resistant strains had higher hydrophobicity than sensitive strains in 1 $\mu \mathrm{g} / \mathrm{ml}$ and $4 \mu \mathrm{g} / \mathrm{ml}$, but significant difference was not found in $2 \mu \mathrm{g} / \mathrm{ml}$ ( $\mathrm{P}$ value $=0.642)$. In terms of electron donoracceptor, resistant samples had higher electron donor characteristic in $1 \mu \mathrm{g} / \mathrm{ml}$ and there was no significant difference in the two other concentrations. Differences between resistant and susceptible strains to ampicillin were not found in terms of electron acceptor characteristic in none of the concentrations of antibiotic.

\subsection{Comparison of Sensitive and Resistant to Ciprofloxacin Strains}

F1. Urinary strains: The hydrophobicity and electron donors and acceptor of resistant and sensitive urinary and fecal strains to ciprofloxacin were compared. Concentrations $0.125 \mu \mathrm{g} / \mathrm{ml}, 0.0625 \mu \mathrm{g} / \mathrm{ml}$ and $0.0312 \mu \mathrm{g} / \mathrm{ml}$ were used for urinary strains treatment. Accordingly, it was found that hydrophobicity of resistant strains had significant distance to sensitive strains in concentration $0.0625 \mu \mathrm{g} / \mathrm{ml}$. sensitive strains electron donor characteristic was higher than resistant strains in concentrations $0.125 \mu \mathrm{g} / \mathrm{ml}$ and $0.0312 \mu \mathrm{g} / \mathrm{ml}$ and electron acceptor characteristic of resistant strains was significantly more than sensitive strains in ciprofloxacin concentrations $0.125 \mu \mathrm{g} / \mathrm{ml}$. However, sensitive strains electron acceptor characteristic was more than resistant strains in concentration $0.0625 \mu \mathrm{g} / \mathrm{ml}$, but no significant difference was found between them in concentration 0.0312 $\mu \mathrm{g} / \mathrm{ml}$.

F2. Fecal strains: Comparative study of hydrophobicity and electron donors and acceptor characteristic of resistant and sensitive fecal strains to ciprofloxacin in the presence of four concentrations $(0.25 \mu \mathrm{g} / \mathrm{ml}, 0.0625 \mu \mathrm{g} / \mathrm{ml}, 0.0312 \mu \mathrm{g} / \mathrm{ml}$ and $0.0156 \mu \mathrm{g} / \mathrm{ml}$ ) showed that resistant strains had higher hydrophobicity than sensitive strains in all four concentrations. Also, the results revealed that sensitive strains had higher electron donor characteristic than resistant strains in concentrations $0.0625 \mu \mathrm{g} / \mathrm{ml}$ and $0.0312 \mu \mathrm{g} / \mathrm{ml}$, but the difference was not significant in two other concentrations. Electron acceptor characteristic of resistant strains was significantly higher than the sensitive strains just in 0.0156 $\mu \mathrm{g} / \mathrm{ml}$.

\subsection{Comparison of Sensitive and Resistant to Ciprofloxacin Strains in the Presence of Rhamnolipid}

Comparison of hydrophobicity and electron donoracceptor of sensitive and resistant urinary strains to ampicillin in the presence of rhamnolipid just indicated that resistant to ampicillin strains had higher electron acceptor characteristic than sensitive strains and there was no significant difference in hydrophobicity and electron donor characteristic. There was no significant difference between sensitive and resistant fecal strains in electron donoracceptor characteristic. However, resistant strains hydrophobicity was significantly higher than sensitive strains in examining the hydrophobicity with hexadecane but there was no significant difference in examining the hydrophobicity with decane.

\subsection{Comparison of Sensitive and Resistant to Ampicillin Strains in the Presence of Rhamnolipid}

Also, sensitive and resistant urinary and fecal strains hydrophobicity and electron donor- acceptor characteristic was investigated. On this basis, no significant difference existed between sensitive and resistant strains. Resistant strains to ciprofloxacin had higher hydrophobicity than sensitive strains in evaluation of hydrophobicity in fecal strains, but this difference was not significant in hydrophobicity evaluation by decane. Sensitive and resistant to ciprofloxacin urinary strains had no significant difference in term of electron donor- acceptor. Also, there was no significant difference between sensitive and resistant strains hydrophobicity.

\section{Discussion}

The aim of this study was to evaluate two surface characteristics (hydrophobicity and electron donor- electron acceptor) of E. coli and the influence of antibiotic and biosurfactant rhamnolipid on them. According to studies, the physico- chemical properties of bacterial surface can be affected by environmental conditions change [3]. The results showed that rhamnolipid and ciprofloxacin and to a lesser amount, ampicillin are able to change the surface characteristics which can finally result in the modification of bacterial attachment to. In this study, it was investigated hydrophobicity and electron donor- electron acceptor of 40 E. coli strains that isolated from urinary tract infections and fecal samples. Hydrophobicity is most important surface physico- chemical characteristic in bacterial adhesion to surfaces [13] and MATS method was used to investigate this issue whose basis is the attachment and bacterial tendency to hydrocarbon solvents [27]. This study confirms the effects of antibiotics SubMIC on hydrophobicity and electron donorelectron acceptor, while this effect is not limited to E. coli and a wide range of bacteria are included [21]. There are reports suggesting that some antibiotics can cause changes in the surface properties and subsequently in the pattern of attachment [28, 21]. Ciprofloxacin is widely used in treatment of diseases related to urinary tract infection due to the low toxicity, Oral consumption as well as long-term bactericidal properties against bacteria [21]. On the other hand, there are many studies that suggest ampicillin resistance duo to the widespread use. This study results indicate that fecal strains had significantly higher hydrophobicity than urinary strains. The results of this study are corroborant of most strains sensitivity to ciprofloxacin in contrast to the ampicillin that reveals high resistance. Ciprofloxacin was more effective in changing the hydrophobicity and electron donor- electron acceptor characteristic in comparison to ampicillin, this fact could indicate the effect of antibiotic-resistance in bacterial surface properties [29]; however, further investigation is needed to 
ensure this topic. Ampicillin decreased hydrophobicity and increased electron acceptor characteristics in most concentrations, despite the less effect of ampicillin compared to ciprofloxacin. However, the irregular and non-linear behavior was observed in ampicillin effects on surface properties. Tahmourespour et al. confirmed the effect of antibiotic resistance on hydrophobicity [29]. The results also confirmed the study of Kustos et al. that in which bacterial treatment with antibiotics led to reduce in hydrophobicity characteristic [24]. Rhamnolipid increased electron donor characteristic and hydrophobicity significantly in almost all cases in urinary samples. This study showed that rhamnolipid and ciprofloxacin have different effects on hydrophobicity, so that rhamnolipid increased and ciprofloxacin decreased it. Also, rhamnolipid increased electron donor characteristic whereas ciprofloxacin increased electron acceptor characteristic. In the study of Feng et al. rhamnolipid increased hydrophobicity of Pseudomonas putida 852 and decreased hydrophobicity of Rhodococcus erythropolis 3586 which revealed that the biosurfactants effect depends on the type of bacteria, the type, and concentration of used surfactant [30]. The hydrophobicity can be associated to the change in the pattern of the surface structure, the thickness of the outer layers, such as capsules, biofilm structure, outer membrane proteins (OMP), and lipopolysaccharide [21]. Observations and results suggest the differences in the hydrophobicity and electron exchange between urinary and fecal strains before and after bacterial treatment with antibiotics and rhamnolipid. When comparing the hydrophobicity of antibiotic sensitive and resistant strains, it was shown that resistant strains have higher hydrophobicity than sensitive strains.

The effect of electron donor and acceptor characteristic on bacterial adhesion is widely investigated [31] .It can indicate the presence of chemical groups in the surface of the bacteria. For example, the electron donor characteristic could indicate the presence of chemical groups with negative charge such as carboxyl, amino $\left(\mathrm{NH}_{2}\right)$, and phosphate $\left(\mathrm{PO}_{4}\right)$ groups and electron acceptor characteristic indicates the presence of acidic groups $\left(\mathrm{NH} 3{ }^{+}\right)$and hydroxyl $(\mathrm{OH})$ on the surface of bacteria [32]. E. coli was strong electron donor and weak electron acceptor in study of Rivas et al. Also, these characteristics were close in planktonic and sessile form [31]. Wojnicz et al. confirmed results of this study in terms of uropathogenic Escherichia coli hydrophobicity levels. Also, ciprofloxacin decreased hydrophobicity of E. coli in cited study [21]. However, this reduction varied in different concentrations according to this study. Generally, this study confirmed different surface characteristics of bacteria in different environmental conditions and direct linkage between them which has been reported in various studies. Tahmourespour et al. showed that Physico-chemical properties of bacteria isolated from different parts of the mouth are different that confirms the differences in hydrophobicity of the urine and fecal strains (With different origins) in this study [29]. However, in some studies, such as the Rivas et al. all of the E. coli is hydrophilic, although all of the E. coli had higher electron donor characteristic than electron acceptor characteristic [31]. It could be due to differences in sample storage conditions, environmental conditions and the origin of the samples [31]. This study could observe the effect of environmental conditions on the surface physicochemical properties of bacteria, such as study of Hamadi et al. where it was found that the $\mathrm{pH}$ and ionic concentration of the surrounding environment can affect the hydrophobicity and electron donor and acceptor characteristic. However, E. coli samples of the study of Hamadi et al. were hydrophilic. The mentioned opposition can be due to the use of standard strains and low statistical population in study of Hamadi et al. in which used of smaller number of strains as representative of other groups. Environmental conditions such as $\mathrm{pH}$, ionic strength, type of medium, serum, the presence of antibiotics, temperature, etc. can affect the physicochemical properties of bacterial surface [12].

\section{Conclusion}

Adhesion is a main stage in pathogenesis of bacteria. In this study showed that some materials such as antibiotics have an ability of change in physicochemical properties of bacterial surface that is result is change in pattern or halt of adhesion. This study showed that inhibition of bacterial adhesion is not impossible. This feature cab be used in the fields of medicine, research, food industry, inhibit the development of antibiotic resistance.

\section{Acknowledgements}

Ailar Jamalli developed the original idea and the protocol. Design, carry out and conduct of the study collection performed by Mahdi Khangholi. Analysis of the data performed by Mohammad Ariaei. Preparation, peer review, and approval of the manuscript performed by Dr. Ailar Jamalli. Review performed by Prof. Ezzatollah Ghaemi, Dr. Shaghayegh Anvari, Thanks all.

\section{Financial Disclosure}

The cost of the project has been funded by Golestan University of medical sciences. This study was supported by Golestan University of medical sciences.

\section{References}

[1] Habimana O, Semião A, Casey E. The role of cell-surface interactions in bacterial initial adhesion and consequent biofilm formation on nanofiltration/reverse osmosis membranes. Journal of Membrane Science. 2014;454:8296.

[2] Wizemann TM, Adamou JE, Langermann S. Adhesins as targets for vaccine development. Emerging infectious diseases. 1999;5(3):395. 
[3] Bardiau M, Szalo M, Mainil JG. Initial adherence of EPEC, EHEC and VTEC to host cells. Veterinary research. 2010;41(5):57.

[4] Hori K, Matsumoto S. Bacterial adhesion: From mechanism to control. Biochemical Engineering Journal. 2010;48(3):424-34.

[5] Busscher HJ, van der Mei HC. How do bacteria know they are on a surface and regulate their response to an adhering state. Plos pathog. 2012;8(1):e1002440-e.

[6] Tenke P, Kovacs B, Jäckel M, Nagy E. The role of biofilm infection in urology. World journal of urology. 2006;24(1):1320.

[7] Hsu LC, Fang J, Borca-Tasciuc DA, Worobo RW, Moraru CI. Effect of micro-and nanoscale topography on the adhesion of bacterial cells to solid surfaces. Applied and environmental microbiology. 2013;79(8):2703-12.

[8] Krachler AM, Orth K. Targeting the bacteria-host interface: strategies in anti-adhesion therapy. Virulence. 2013;4(4):28494.

[9] Saralaya V, Bhat G, Kamath A, Shivananda P. Effect of trace elements on surface hydrophobicity and adherence of Escherichia coli to uroepithelial cells. Indian J Exp Biol. 2004;42:681-5.

[10] Pizarro-Cerda J, Cossart P. Bacterial adhesion and entry into host cells. Cell. 2006;124(4):715-27.

[11] Katsikogianni M, Missirlis Y. Concise review of mechanisms of bacterial adhesion to biomaterials and of techniques used in estimating bacteria-material interactions. Eur Cell Mater. $2004 ; 8(3)$.

[12] Hamadi F, Latrache H, El Ghmari A, Ellouali M, Mabrrouki $\mathrm{M}$, Kouider N. Effect of $\mathrm{pH}$ and ionic strength on hydrophobicity and electron donor and acceptor characteristics of Escherichia coli and Staphylococcus aureus. ANNALS OF MICROBIOLOGY. 2004;54:213-26.

[13] Oliveira R, Azeredo J, Teixeira P, Fonseca A. The role of hydrophobicity in bacterial adhesion. 2001.

[14] Gottenbos B, Grijpma DW, van der Mei HC, Feijen J, Busscher HJ. Antimicrobial effects of positively charged surfaces on adhering Gram-positive and Gram-negative bacteria. Journal of antimicrobial chemotherapy. 2001;48(1):7-13.

[15] Burton E, Gawande PV, Yakandawala N, LoVetri K, Zhanel GG, Romeo T, et al. Antibiofilm activity of GlmU enzyme inhibitors against catheter-associated uropathogens. Antimicrobial agents and chemotherapy. 2006;50(5):1835-40.

[16] Nataro JP, Kaper JB. Diarrheagenic escherichia coli. Clinical microbiology reviews. 1998;11(1):142-201.

[17] Jacobsen S, Stickler D, Mobley H, Shirtliff M. Complicated catheter-associated urinary tract infections due to Escherichia coli and Proteus mirabilis. Clinical microbiology reviews. 2008;21(1):26-59.

[18] Galdiero S, Falanga A, Cantisani M, Tarallo R, Della Pepa ME, D'Oriano V, et al. Microbe-host interactions: structure and role of Gram-negative bacterial porins. Current protein \& peptide science. 2012;13(8):843.

[19] Al-Tahhan RA, Sandrin TR, Bodour AA, Maier RM. Rhamnolipid-induced removal of lipopolysaccharide from Pseudomonas aeruginosa: effect on cell surface properties and interaction with hydrophobic substrates. Applied and Environmental Microbiology. 2000;66(8):3262-8.

[20] Zeraik AE, Nitschke M. Biosurfactants as agents to reduce adhesion of pathogenic bacteria to polystyrene surfaces: effect of temperature and hydrophobicity. Current microbiology. 2010;61(6):554-9.

[21] Wojnicz D, Jankowski S. Effects of subinhibitory concentrations of amikacin and ciprofloxacin on the hydrophobicity and adherence to epithelial cells of uropathogenic Escherichia coli strains. International journal of antimicrobial agents. 2007;29(6):700-4.

[22] Madani SH, Khazaee S, Kanani M, Shahi M. Antibiotic resistance pattern of $\mathrm{E}$. coli isolated from urine culture in Imam Reza Hospital Kermanshah-2006. Journal of Kermanshah University of Medical Sciences (J Kermanshah Univ Med Sci). 2008;12(3).

[23] Abdollahi Kheirabadi S, Najafipour S, Kafilzadeh F, Abdollahi A, Jafari S, Moravej A. Evaluation of Drug Resistance Pattern of Escherichia coli Strains Isolated from Fasa Vali-e-Asr Hospital Patients. Journal of Fasa University of Medical Sciences. 2013;2(4):273-8.

[24] Kustos T, s a, Kustos I, oacute, Kilár F, Rappai G, et al. Effect of antibiotics on cell surface hydrophobicity of bacteria causing orthopedic wound infections. Chemotherapy. 2003;49(5):237-42.

[25] Wiegand I, Hilpert K, Hancock RE. Agar and broth dilution methods to determine the minimal inhibitory concentration (MIC) of antimicrobial substances. Nature protocols. 2008;3(2):163-75.

[26] Sodagari M, Wang H, Newby B-mZ, Ju L-K. Effect of rhamnolipids on initial attachment of bacteria on glass and octadecyltrichlorosilane-modified glass. Colloids and Surfaces B: Biointerfaces. 2013;103:121-8.

[27] Bellon-Fontaine M-N, Rault J, Van Oss C. Microbial adhesion to solvents: a novel method to determine the electrondonor/electron-acceptor or Lewis acid-base properties of microbial cells. Colloids and Surfaces B: Biointerfaces. 1996;7(1):47-53.

[28] Baskin H, Doğan Y, Bahar IH, Yuluğ N. Effect of subminimal inhibitory concentrations of three fluoroquinolones on adherence of uropathogenic strains of Escherichia coli. International journal of antimicrobial agents. 2002;19(1):79-82.

[29] Tahmourespour A, Kasra KR, SALEHI R, NABINEZHAD A. The relationship between cell surface hydrophobicity and antibiotic resistance of streptococcal strains isolated from dental plaque and caries. 2008.

[30] Feng W, Swift S, Singhal N. Effects of surfactants on cell surface tension parameters and hydrophobicity of Pseudomonas putida 852 and Rhodococcus erythropolis 3586. Colloids and Surfaces B: Biointerfaces. 2013;105:43-50.

[31] Rivas L, Fegan N, Dykes G. Physicochemical properties of Shiga toxigenic Escherichia coli. Journal of applied microbiology. 2005;99(4):716-27.

[32] Djeribi R, Boucherit Z, Bouchloukh W, Zouaoui W, Latrache $\mathrm{H}$, Hamadi F, et al. A study of $\mathrm{pH}$ effects on the bacterial surface physicochemical properties of Acinetobacter baumannii. Colloids and Surfaces B: Biointerfaces. 2013;102:540-5. 